\title{
Barriers to cervical cancer screening: A qualitative study among Somali women in Oslo Norway
}

\author{
Mohammed-nur A Addawe, Christina Brux Mburu and Ahmed A Madar* \\ Department of Community Medicine and Global Health, Institute of Health and Society, University of Oslo, Norway
}

\begin{abstract}
Background: Research findings suggest that immigrant women are less likely to participate in cervical cancer screening. Increased understanding of the barriers confronted and possibilities for facilitating screening participation is needed.

Methods: Interviews and focus group discussions were conducted among 57 Somali women in Oslo to explore experiences with and perceptions of cervical cancer screening.

Results: The study revealed a lack of familiarity with cervical cancer and perceived irrelevance of screening, emotional barriers such as fear and embarrassment, practical challenges related to childcare, and language, cultural and religious concerns related to modesty and sexuality, and mistrust. Participant suggestions for reducing these barriers and facilitating screening participation included awareness creation, translated materials, and female practitioners.
\end{abstract}

Conclusion: Accounting for these barriers, implementing these recommendations, and better attuning the screening program to the present-day multicultural population of Norway can potentially increase participation in cervical cancer screening among Somali and potentially other immigrant women.

\begin{abstract}
Abbreviations: CCS: Cervical cancer screening; CRN: Cancer Registry of Norway; FGD: Focus Group Discussion; FGM: Female Genital Mutilation; GD: Group discussion; GP: General Practitioner; HPV: Human Papilloma Virus; NSD: Norwegian Center for Research Data; PAP: The Papanicolaou test; REC: Norwegian Regional Committees for Medical and Health Research

\section{Background}

Globally, cervical cancer ranks as the fourth most common form of cancer affecting women, with an estimated 528,000 new cases in 2012 [1]. In developing countries, cervical cancer ranks as the second most common type of cancer affecting women [2]. In 2012, 266,000 deaths occurred worldwide as a result of cervical cancer, and more than $85 \%$ of these deaths occurred in low- and middle-income countries [1]. In Sub-Saharan Africa, cervical cancer is the leading cause of cancerrelated mortality, with more than 75,000 new cases and over 50,000 deaths reported each year [2]. Human papilloma virus is the leading cause of cervical cancer, with over 70\% cases caused by HPV 16 and 18 [3].
\end{abstract}

Previous studies indicate that cervical cancer screening has reduced cervical cancer morbidity and mortality in Europe [4]. Studies conducted in the United States suggest that cervical cancer-related morbidity and mortality are higher in immigrant than in host populations and that immigrant women may be less likely than non-immigrant women to participate in cervical cancer screening [5]. Somali women have been identified as one particular group less likely to participate in cervical cancer screening [5-7]. The cancer registry of Norway (CRN) sends a screening invitation letter, written in Norwegian, to all women between the ages of 25 and 69. The women are advised to make appointment with their general practitioner for cervical cancer screening. A retrospective register-based study of 1.3 million women in Norway showed that $50 \%$ of immigrant women were non-adherent compared to $31 \%$ of native Norwegians [8]. Nonetheless, statistics about the burden of cervical cancer among immigrant women in Norway are lacking. A recent study about barriers and facilitators to cervical cancer screening among Pakistani and Somali women in Norway revealed three levels of barriers: the individual level consisting of a lack of understanding of screening benefits, the sociocultural level that included stigma related to cervical cancer and the belief that unmarried women are sexually inactive, and the system level that entailed a lack of trust in the health care system [9]. The present study, in addition to exploring barriers to cervical cancer screening among Somali women in Oslo, lent particular attention to their suggestions for reducing them, thus contributing further to our understanding of not only barriers but also potential facilitators to cervical cancer screening among Somali immigrant women in Norway.

\section{Methods}

A qualitative study design was utilized, in which in-depth interviews and focus group discussions were conducted among Somali women to explore their experiences and perceptions of cervical cancer screening, with a particular focus on barriers to screening and their suggestions for reducing them. Prior to initiating the project, research permission was obtained. A remit assessment was first sought from

Correspondence to: Ahmed Madar, Department of Community Medicine and Global Health, Institute of Health and Society, University of Oslo, Post Box 1130 Blindern, 0318 Oslo, Norway, Tel: + 47228506 34; Fax: + 47228505 90; Email: a.a.madar@medisin.uio.no

Key words: cervical cancer screening, Somali women, immigrant women, qualitative research

Received: February 03, 2018; Accepted: February 22, 2018; Published: February 24,2018 
the Norwegian Regional Committees for Medical and Health Research Ethics (REC). REC confirmed that, given the project's qualitative focus on subjective perceptions and perspectives, it was not subject to the Health Research Act and could be conducted without approval from this entity. The project and detailed information about its aim, recruitment strategy, methodology and procedures for data storage and processing was therefore reported to the Norwegian Centre for Research Data (NSD). NSD approved of the project and the project was conducted accordingly. Written informed consent was obtained from all participants.

\section{Participant sample and recruitment}

The study sample consisted of 57 first generation Somali women aged 25 and above and residing in Oslo. Purposive sampling was used to identify and select information-rich cases related to the research objective [10]. This was achieved by striving for maximum variation with respect to age, marital status, education and duration of residency in Norway in the interest of achieving a heterogeneous sample. Recruitment was carried out by the researcher and a research assistant in different geographic areas of Oslo and various social settings, which included community gatherings, business premises, and mosques.

\section{Data collection}

Data collection consisted of 15 in-depth interviews, four focus group discussions (FGDs) with approximately eight participants each, and two group discussions consisting of three and five participants respectively. The interviews and FGDs were conducted between September and December 2016. A semi-structured, thematic guide of open-ended questions was utilized during the interviews, which enabled the participants to share their experiences and perspectives freely and the researcher to adapt the interviews accordingly. The interviews were conducted in the women's homes and at community centers, in quiet and private spaces, free of interruptions and in which confidentiality was achieved. The FGDs were conducted at community centers located in the areas in which the women resided. Each of the indepth interviews lasted about an hour, and the FGDs lasted about one to one and a half hours. Five of the in-depth interviews were conducted in English. The rest of the data collection was conducted in Somali. With the permission of the research participants, all of the data collection was audio recorded and transcribed by the first author. Data collection was carried out in pursuit of a meaningful degree of saturation, with saturation referring to the point at which the significance of new findings and additional data collection diminished and a meaningful coherence among the data emerged [11].

\section{Data analysis}

Initial forms of data analysis began during the data collection process, which enabled emerging themes to be identified and further explored as the data collection evolved accordingly. Upon the completion of the data collection, an iterative, systematic, and comprehensive process of thematic content analysis was performed. Initially, all the transcripts were read and re-read to establish familiarity with the data and the context in which it was collected [12]. Initial codes were developed by the first author, applied to the entire data set, adapted, and closely examined to ensure that they reflected the contents of the data material. As descriptive codes evolved into more analytic ones, a set of themes was established and analyzed by all three authors.

\section{Results}

Fifty-seven first generation Somali women were recruited both for the in-depth-interviews and focus group discussions. The age of the participants ranged from 25 to 56 years. More than half of the women were married $(\mathrm{N}=30)$, while the remaining were unmarried $(\mathrm{N}=27)$. Similarly, the majority of the women had some level of formal education, while few had higher education $(\mathrm{N}=5)$. The duration of stay in Norway ranged from 2 to 25 years.

\section{Barriers to cervical cancer screening}

The study identified five types of barriers to cervical cancer screening: (1) lack of familiarity with cervical cancer and perceived irrelevance of cervical cancer screening, (2) emotional barriers, (3) practical barriers, (4) cultural and religious concerns, and (5) mistrust in the health system. Each of the barriers is described below. Quotations are provided in the tables (Table 1).

\section{Lack of familiarity with cervical cancer and perceived irrelevance of screening}

The study participants were largely unfamiliar with cervical cancer and screening. The majority of the women reported that they had not been aware of the disease in Somalia, where screening is rare, and that it had come to their attention only after immigrating to Norway (Table 2, Quotes 1 and 2). In addition, the absence of cervical cancer symptoms was stated as a barrier to cervical cancer screening. Most of the participants believed that, because they lacked symptoms, they were healthy and did not require the screening test (Table 2, Quote 3).

\section{Emotional barriers}

Emotional barriers to cervical cancer screening included fear of the outcome of the test and, in particular, learning that one has cancer, as well as embarrassment, particularly related to exposing oneself during the procedure and due to circumcision (Table 3, Quotes 1, 2 and 3).

\section{Practical barriers}

Practical barriers included a lack of time and language difficulties. Most of the women described having many responsibilities at home and with respect to caring for children. Due to competing demands on their time, some of the participants described having to prioritize these other responsibilities and appointments (Table 4, Quote 1 and 2). One of the participants, when emphasizing the importance of prioritizing children, described fear of the child protection services (Table 4, Quote 3). Additionally, language was frequently described as a barrier. The majority of the participants, and the older generation especially, stated they were not fluent in Norwegian and were thus unable to understand the contents of the screening invitation letter (Table 4, Quote 4).

\section{Cultural and religious concerns}

Concerns about matters important within Somali culture and faith were described by the participants as rendering them reluctant to participate in screening. Most the participants stated that the Pap smear test was invasive and could damage their virginity (Table 5, Quote 1). Furthermore, most of the participants explained that the test compromised their values of modesty, given their belief that women are not supposed to show their body to strangers (Table 5, Quote 2). In addition, most of the participants stated that they were not comfortable with a male doctor or gynaecologist (Table 5, Quote 3). Furthermore, a fatalistic belief about cervical cancer was identified as a barrier to screening, and most of the participants believed that it is through God's destiny that one gets cancer (Table 5, Quote 3 and 4). 
Table 1. characteristic of the study population. "Unmarried category includes single / divorced/separate and widowed.

\begin{tabular}{|c|c|}
\hline Variables & $\mathbf{N}(\%)$ \\
\hline \multicolumn{2}{|l|}{ Age, years } \\
\hline $25-35$ & $22(39 \%)$ \\
\hline $36-45$ & $19(33 \%)$ \\
\hline $46+$ & $16(28 \%)$ \\
\hline \multicolumn{2}{|l|}{ Marital status } \\
\hline Unmarried & $27(47 \%)$ \\
\hline Married & $30(53 \%)$ \\
\hline \multicolumn{2}{|l|}{ No of children } \\
\hline $0-3$ & $25(44 \%)$ \\
\hline$>3$ & $32(56 \%)$ \\
\hline \multicolumn{2}{|l|}{ Level of education } \\
\hline$\leq$ Secondary school & $52(91 \%)$ \\
\hline$>$ Secondary school & $5(9 \%)$ \\
\hline \multicolumn{2}{|c|}{ Duration of stay (years) } \\
\hline $2-13$ & $22(39 \%)$ \\
\hline $13+$ & $35(61 \%)$ \\
\hline
\end{tabular}

Table 2. Lack of familiarity with cervical cancer and perceived irrelevance of screening. \begin{tabular}{|l|l|}
\hline Quotes & $\begin{array}{l}\text { "Back in our home country nobody used to talk about this disease, and there } \\
\text { was no awareness about it. [...) but as for me, I started hearing about cervical } \\
\text { cancer in Norway. I used to hear this person died of "Kansar" (cancer) } \\
\text { but this specific type of cancer I have not heard about it before." (FGD4 } \\
\text { Participant 2). }\end{array}$ \\
\hline 2 & $\begin{array}{l}\text { "What I can say as the main obstacle to the screening is the unfamiliarity of } \\
\text { the screening test. We are new in Norway and we never used to have such } \\
\text { tests in our home country." (FGD2 Participant 6). }\end{array}$ \\
\hline 3 & $\begin{array}{l}\text { "Women don't believe that they have the disease and this makes them not go } \\
\text { for the screening services. Why I personally have not gone for the test is that I } \\
\text { don't believe I have the disease." (Interview 2). }\end{array}$ \\
\hline
\end{tabular}

Table 3. Emotional barriers.

\begin{tabular}{|l|l|}
\hline Quotes & \\
1 & $\begin{array}{l}\text { "Most of the Somali women don't go for the screening because they fear } \\
\text { the outcome. [...]. Most of the women fear to be told that they have cervical } \\
\text { cancer after the screening." (Interview 1). }\end{array}$ \\
\hline 2 & $\begin{array}{l}\text { "When I got the invitation letter I haven't gone for the test because I feared } \\
\text { the outcome of the test." (FGD2 Participant 7). }\end{array}$ \\
\hline 3 & $\begin{array}{l}\text { "For most of the people, the procedure does not excite them. The older } \\
\text { generation might feel embarrassed about taking this test because of the female } \\
\text { genital mutilation (FGM). The fear is exposing themselves to the doctor, and I } \\
\text { think a lot of women do." (Interview 7). }\end{array}$ \\
\hline
\end{tabular}

\section{Mistrust in the health system}

When the participants were asked about the barriers to cervical cancer screening, the issue of trust came up, especially in the focus group discussions. One participant mentioned that she could not trust the person examining her, which was particularly concerning given the importance of the organ being examined (Table 6, Quote 1). Similarly, participants expressed that their doctors were predominantly concerned about the number of children they had (Table 6, Quote 2) and lamented Norway's lack of Somali doctors, who they would have trusted to share and respect their language, culture, and faith.

\section{Suggestions for reducing barriers to cervical screening}

As the participants identified clear barriers to screening, they were also asked to share their suggestions for reducing these barriers and encouraging more women to participate in screening. The participants proposed increasing awareness through seminars and workshops in local neighbourhoods to inform women about the relevance of the test (Table 7, Quote 1). Similarly, they suggested that GPs encourage their patients to be screened, given that many women have regular contact with their GPs (Table 7, Quote 2). Additionally, the participants suggested the use of translated materials that could be easily understood by the women, such as the invitation letter that is sent out to all women in Norway and information materials that could be made accessible in areas attended frequently by these women, such as the maternal and child health clinics (Table 7, Quote 3). Lastly, the research participants also emphasized the importance of accommodating their preference for having the screening carried out by female doctors or gynaecologists (Table 7, Quote 4).

\section{Discussion}

This study explored barriers to cervical cancer screening among Somali women in Oslo and their suggestions for reducing these. The study findings reveal a lack of familiarity with cervical cancer and screening among the participants, who explained that they had not heard about cervical cancer until immigrating to Norway and receiving the screening invitation letter. This finding is consistent with results from previous studies [13-15]. The study findings also suggest that this, together with a general lack of familiarity with preventative health and tendency to seek health services only when ill, contributed to a perception of cervical cancer screening as unimportant and of little

\section{Table 4. Practical barriers}

\begin{tabular}{|l|l|}
\hline Quotes & $\begin{array}{l}\text { "Some of the women have a lot of work to do at home. Others go to work, } \\
\text { workshops and school. Therefore most of the women say that they don't have } \\
\text { time to go for the test." (GD2 Participant 3). }\end{array}$ \\
\hline 2 & $\begin{array}{l}\text { "I think also many women cannot turn up for their appointments. It's possible } \\
\text { that when you get the invitation, you have a lot of children to take care of or } \\
\text { maybe you may forget the appointment to take the test." (Interview 9). }\end{array}$ \\
\hline 3 & $\begin{array}{l}\text { "Women are busy going after their daily activities like going to schools; they } \\
\text { also have the responsibility of looking after their children. They do this with } \\
\text { the fear of losing their children to the child welfare services." (Interview 12). }\end{array}$ \\
\hline 4 & $\begin{array}{l}\text { "I know many Somali women especially the older generation; I think they } \\
\text { would not take such a test because there is a language barrier. When they } \\
\text { come across a written document, they do not have the skills to understand the } \\
\text { importance of it." (Interview 4). }\end{array}$ \\
\hline
\end{tabular}

Table 5. Cultural and religious concerns.

\begin{tabular}{|l|l|}
\hline Quotes & $\begin{array}{l}\text { "Women are not comfortable with gynaecological examinations, especially } \\
\text { for the younger and unmarried women. They feel that the procedure is } \\
\text { invasive and it will damage their virginity." (Interview 14). }\end{array}$ \\
\hline 2 & $\begin{array}{l}\text { "Some of the women are not comfortable with a male doctor or male } \\
\text { gynaecologist, and they prefer a female doctor to carry out the screening." } \\
\text { (Interview 14). }\end{array}$ \\
\hline 3 & $\begin{array}{l}\text { "Just like me most of the Somali women don't like to be examined, and we } \\
\text { believe that it's only through the destiny of God that one can get this type of } \\
\text { disease." (Interview 9). } \\
\text { "Invitation letters are usually sent but some women are not interested in going } \\
\text { for the test. They say it's through God's fate that one gets the disease and he } \\
\text { is the one who cures it." (FGD 3 Participant 5). }\end{array}$ \\
\hline 4 &
\end{tabular}

Table 6. Mistrust in the health system.

Quotes

"There are many things that can cause doubt, for example, you can't tell whether the person examining you is helping you or deceiving you. Since 1 an important organ is being tested, it can happen that you might not trust the person examining you." (FGD1 Participant 2).

"[...] each one of them asks you, do you come from Somalia, how many children do you have? Are you looking for another child? This becomes a challenge to go and do the test. This is what I believe are the obstacles to the cervical cancer screening. [...]This makes us use private GPs when we have our own GPs; this is due to lack of good reception and welcome from our own GPs." (FGD 1 Participant 3). 
Table 7. Suggestions for reducing barriers to cervical screening.

\begin{tabular}{|l|l|}
\hline Quotes & $\begin{array}{l}\text { "We need information about the disease. Seminars and workshops should } \\
\text { be conducted in all the neighbourhoods so that the women can be well } \\
\text { informed. Women should be taught how they can prevent themselves from } \\
\text { the diseases." (Interview 12). }\end{array}$ \\
\hline 2 & $\begin{array}{l}\text { "The GPs also need to encourage women to go for the screening since many } \\
\text { women have contact with their GPs." (GD1 Participant 6). }\end{array}$ \\
\hline 3 & $\begin{array}{l}\text { "I think just having brochures and information packs in Somali language } \\
\text { might help especially in designated areas like the health clinics especially } \\
\text { when they go for the antenatal check-ups." (Interview 7). } \\
\text { "Another way to increase attendance of the cervical cancer screening is we } \\
\text { need a female doctor or gynaecologist." (FGD 2 Participant 3). }\end{array}$ \\
\hline 4
\end{tabular}

relevance for the research participants. Similar findings have been reported in a study conducted among ethnic minorities in the U.K., where immigrant women were more likely to believe that they do not need a smear test if they do not have symptoms [16].

As reported in previous studies, embarrasment, fear of the outcome of the test, lack of time, and language difficulties have been identified as barriers by this study $[13,14,17,18]$. A finding unique to this study is the fear of child protection services. The Norwegian child protection services has a poor reputation among many immigrants. In particular, there is a concern among parents that they will not be listened to, understood or believed and, ultimately, that they might lose custody of children on unfair grounds [19]. This findings suggest that a negative relationhip with one aspect of the welfare state like the child welfare protection services can have important consequences for their relation to another.

Findings from the study also identified cultural and religious concerns as barriers to cervical cancer screening. The study findings that the Pap smear test was perceived as potentially conflicting with cultural and religious values about sexuality and modesty, considered invasive, and understood as potentially compromising the virginity of young and unmarried women are consistent with a previous study among Somali women [18], as well as with a recent study among Pakistani and Somali women in Oslo that found that unmarried women are not expected to undergo screening due to cultural and religious expectations that they remain sexually inactive until married [9] The study findings that the research participants prefered female practitioners and avoided screening due to concern that they might be met by a male practitioner are also similar to the findings of previous studies conducted among Somali women $[13,15]$. Also consistent with other studies was that the participants believed that the presence or absence of disease was a matter of God's will, which also then coincided with fatalistic attitudes about not only the development of cervical cancer, but also its outcome $[13,20,21]$. That most of the participants stated that they did not believe in getting cervical cancer and therefore did not need to be screened suggests that religious beliefs have an important influence on health decisions and health seeking behaviour.

The study findings have identified mistrust of the health system as a barrier to cervical cancer screening. The finding that the research participants did not fully trust the doctors who might examine them is consistent with the findings of a previous study in which mistrust of the health system was based on reports from friends or relatives regarding problems that they had encountered [20,22]. Furthermore, the study findings also revealed a poor doctor-patient relationship, in which the participants perceived themselves as poorly received and their doctors as predominantly and problematically concerned about the number of children they chose to have, as a barrier to screening. A recent study about barriers and facilitators to cervical cancer screening among Pakistani and Somali women attributed lack of trust in the health care system to language, cultural, and gender-related barriers
[9]. Trust has conventionally been regarded as the cornerstone of an effective doctor-patient relationship [23]. The GPs serve as a first contact point and play a significant role in perceptions of health services [17]. As suggested by these findings, the relationship that women have with their GPs and other health providers at the primary health care level is of potential importance to their decisions about whether or not they participate in screening services. Furthermore, the study findings suggest that, in addition to involving the GPs, raising awareness, making information materials written in Somali accessible in places frequented by Somali women, and ensuring that preferences for a female doctor are accommodated are promising strategies for potentially increasing participation in cervical cancer screening. This is consistent with findings from a recent study [9]. Finally, the study suggests use of interactive social media such as SMS and other social websites that have the potential for increasing participation as highlighted by a recent study [9].

The use of a relatively large sample is an asset for this study, since it contributed to a range of diversity and captured differing views and experiences. Similarly, the triangulation of data collection methods enabled a comprehensive exploration, from different angles, of the study phenomenon and thereby enhanced the trustworthiness of our data material. Nonetheless, the inclusion of only first generation women as study participants might limit the transferability of the study to younger women of Somali background, who might have a different view of the topic under study. Even though we made efforts to mediate and assess the presence of a male researcher during the interviews, we cannot be entirely sure of the effect this might have had on the responses of the participants.

Despite these limitations, the study has arrived at a number of recommendations that have the potential to increase women participation in cervical cancer screening. This study supports the suggestion of a recent study that recommended developing a culturallytailored intervention to potentially increase participation in cervical cancer screening among Somali and other immigrant women in Norway [9]. A previous study that accounted for the views of Somali women and men demonstrated that faith-based messages can potentially reinforce the views of those already inclined to screening and encourage those with reservations [22]. Therefore, this study recommends the use of faithbased messages by engaging local imams who might dispel or at least mediate fatalistic understandings and address concerns about matters of modesty and sexuality as part of an intervention alongside other practical suggestions raised by the participants. Another study showed that prompting from GPs motivated women to attend cervical cancer screening [23], and this study hence also recommends the involvement of health providers, particularly the GPs who serve as regular contacts for the women, in encouraging the women to take the Pap smear test. A closer examination of the impact of the child protection services on cervical cancer screening uptake is also recommended by the study. Finally, the study calls for more research about this topic that explores the perspectives of health providers.

\section{Conclusion}

The study revealed lack of familiarity with cervical cancer and screening as a barrier to the Pap smear test. In addition to emotional barriers such as fear of the outcome of the test and embarrasment linked the practice of FGM, the study findings highlighted practical issues related to child care, language difficulties, cultural and religious concerns, as well as mistrust of the health care system as barriers to cervical cancer screening. Any future interventions should account for these barriers, consider the study recommendations and adapt the 
cervical cancer screening program in ways that can accommodate the present-day multicultural population of Norway, which can potentially increase participation in cervical cancer screening among Somali and possibly other immigrant women as well.

\section{Declarations}

\section{Authors' contributions}

Each of the authors has taken part in the development, implementation of methods and preparation of the manuscript. MAA collected data and produced the first draft of the manuscript. AAM and CBM reviewed on the draft, contributed to the interpretation of the findings and all authors approved the final version of the manuscript.

\section{Acknowledgements}

The authors would like to thank and acknowledge the participants of this study for sharing their valuable experiences and time. Similarly, the authors wish to recognize the contributions of the research assistant Arifi Mohamoud for recruitment and contribution of data collection.

\section{Competing interests}

The authors declare that they have no competing interests.

\section{Availability of data and materials}

Permission to share data can be obtained from the authors, should any information be required regarding used data, it can be requested from the corresponding author who will then communicate with the other authors.

\section{Consent for publication}

This manuscript contains no individual person's data, images or videos (except for contact details for co-authors) and no case reports are included.

\section{Ethics approval and consent to participate}

Norwegian Centre for Research Data (NSD) (Ref: 49177/3/ HIT). Written informed consent was obtained from all participants.

\section{Funding}

This study was funded by the Institute of Health and Society, University of Oslo.

\section{Open Access}

This article is distributed under the terms of the Creative Commons Attribution 4.0 International License (http://creativecommons.org/ licenses/by/4.0/), which permits unrestricted use, distribution, and reproduction in any medium, provided you give appropriate credit to the original author(s) and the source, provide a link to the Creative Commons license, and indicate if changes were made. The Creative Commons Public Domain Dedication waiver (http://creativecommons. org/publicdomain/zero/1.0/) applies to the data made available in this article, unless otherwise stated.

\section{References}

1. Ferlay J, Soerjomataram I, Dikshit R, Eser S, Mathers C, et. al, (2012) Cancer incidence and mortality worldwide: sources, methods and major patterns in GLOBOCAN 2012. Int $J$ Cancer 136: E359-E386.

2. Adewole IF (2013) Consensus recommendations for the prevention of cervical cancer in sub-Saharan Africa. Southern African Journal of Gynaecological Oncology 5: 47-57.

3. WHO (2014) Comprehensive Cervical Cancer Control. (2nd Edn) A guide to essential practice pp. $25-45$.
4. Azerkan F, Widmark C, Sparén P, Weiderpass E, Tillgren P, et al. (2015) When life got in the way: How danish and norwegian immigrant women in Sweden reason about cervical screening and why they postpone attendance. PloS one 10: e0107624.

5. Harcourt N, Ghebre RG, Whembolua GL, Zhang Y, Osman SW, et al. (2014) Factors associated with breast and cervical cancer screening behavior among African immigrant women in Minnesota. Journal of Immigrant and Minority Health 16: 450-456.

6. Morrison TB (2012) Disparities in preventive health services among Somali immigrants and refugees. Journal of immigrant and minority health 14: 968-974.

7. Samuel PS, Pringle JP, James NW, Fielding SJ, Kathleen M, et al. (2009) Breast, cervical, and colorectal cancer screening rates amongst female Cambodian, Somali, and Vietnamese immigrants in the USA. Int J Equity Health 8: 30.

8. Leinonen MK (2017) Personal and provider level factors influence participation to cervical cancer screening: A retrospective register-based study of 1.3 million women in Norway. Preventive Medicine 94: 31-39.

9. Gele AA, Qureshi SA, Kour P, Kumar B, Diaz E et al. (2017) Barriers and facilitators to cervical cancer screening among Pakistani and Somali immigrant women in Oslo: a qualitative study. Int $J$ Womens Health 9: 487-496.

10. Mack N (2005) Qualitative research methods: a data collectors field guide. P. 1-12.

11. Dahlgren LM, Emmelin M, Winkvist A (2007) Qualitative methodology for international public health. Department of Public Health and Clinical Medicine p. 66-94.

12. Kielmann KF, Cataldo F, Seeley C (2011) Introduction to qualitative research methodology. UK: Write--Arm. DFID pp. 64 - 68.

13. Abdullahi A, Copping J, Kessel A, Luck M, Bonell C (2009) Cervical screening: Perceptions and barriers to uptake among Somali women in Camden. Public health 123: $680-685$.

14. Raymond NC, Osman W, O'Brien JM, Ali N, Kia F, et al. (2014) Culturally informed views on cancer screening: a qualitative research study of the differences between older and younger Somali immigrant women. BMC Public Health 14: 1188.

15. Carroll J, Epstein R, Fiscella K, Volpe E, Diaz K, et al. (2007) Knowledge and beliefs about health promotion and preventive health care among Somali women in the United States. Health Care Women Int 28: 360-380.

16. Marlow LAV, Wardle J, Waller J (2015) Understanding cervical screening nonattendance among ethnic minority women in England. Br J Cancer 113: 833-839.

17. Marlow LA, Waller J, Wardle J (2015) Barriers to cervical cancer screening among ethnic minority women: a qualitative study. J Fam Plann Reprod Health Care 41: 248-254.

18. Ghebre RG (2015) Cervical cancer: barriers to screening in the Somali community in Minnesota. Journal of Immigrant and Minority Health 17: 722-728.

19. Studsrød I, Willumsen E, Ellingsen IT (2014) Parents' perceptions of contact with the Norwegian Child Welfare Services. Child \& Family Social Work 19: 312-320.

20. Raymond NC (2014) Culturally informed views on cancer screening: a qualitative research study of the differences between older and younger Somali immigrant women. BMC public health 14: 1188.

21. Morrison TB, Flynn PM, Weaver AL, Wieland ML (2013) Cervical cancer screening adherence among Somali immigrants and refugees to the United States. Health Care Women Int 34: 980-988.

22. Pratt R (2017) Views of Somali women and men on the use of faith-based message promoting breast and cervical cancer screening for Somali women: a focus-group study. BMC Public Health 17: 270.

23. O'Connor M (2014) Motivators for women to attend cervical screening: the influential role of GPs. Family practice p. cmu029.

Copyright: (C2018 Addawe MA. This is an open-access article distributed under the terms of the Creative Commons Attribution License, which permits unrestricted use, distribution, and reproduction in any medium, provided the original author and source are credited. 